\title{
Take-away container impacts
}

J. Cleaner Prod. 211, 417-427 (2019)

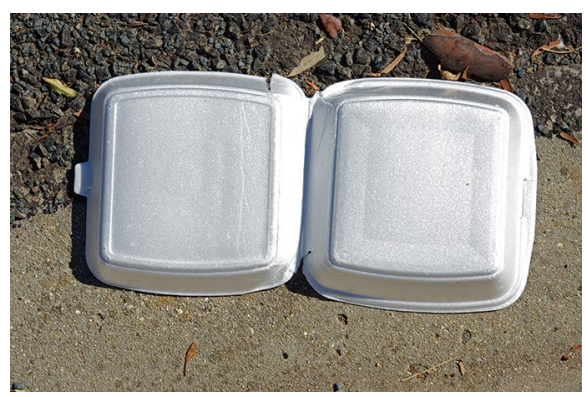

Credit: SIMON MCGILL / GETTY

Dining in is the new dining out. More people worldwide are eating take-away food, and this trend will only increase with development and urbanization. Take-away food containers, often hard to re-use and to recycle, generate litter and populate landfills. Illuminating the impacts of different options could promote more-informed choices.

Alejandro Gallego-Schmid, of the University of Manchester, United Kingdom, and colleagues estimated impacts of the three most-used types: aluminium (with paper lid), extruded polystyrene (EPS; rigid foam plastic), and polypropylene (PP; often-translucent plastic in takeaway and reusable varieties). Authors focused on the European Union and on single use of $670 \mathrm{ml}$ containers, the latter to reflect common consumer habits and with the aim of holding waste generation constant. They considered comparable life cycles, from production to disposal, across 12 impact categories, including toxicity to humans and marine life, global warming impacts and energy demand. For these 12 impacts, they found EPS to be the best option. Re-use moderates these impacts, but, for example, the sturdier polypropylene option must be used 16 times or more to be comparable, depending on which impact is being assessed. Importantly, all generate waste. Unless we change our habits and options, our takeaway society will continue to be a throwaway society.

William Burnside

Published online: 10 January 2019

https://doi.org/10.1038/s41893-018-0216-8 